Abstracta Iranica Abstracta Iranica

Revue bibliographique pour le domaine irano-aryen

Volume 26 | 2005

Comptes rendus des publications de 2003

\title{
"Literary canon and patterns of evaluation in Persian prose of the eve of the Mongol invasion ». Studia Iranica, 32, 1, (2003), pp. 47-76.
}

Justine Landau

\section{(2) OpenEdition}

Journals

Édition électronique

URL : http://journals.openedition.org/abstractairanica/2077

ISSN : 1961-960X

Éditeur :

CNRS (UMR 7528 Mondes iraniens et indiens), Éditions de l'IFRI

Édition imprimée

Date de publication : 15 mai 2005

ISSN : 0240-8910

Référence électronique

Justine Landau, « « Literary canon and patterns of evaluation in Persian prose of the eve of the Mongol invasion ». Studia Iranica, 32, 1, (2003), pp. 47-76. », Abstracta Iranica [En ligne], Volume 26 | 2005, document 383, mis en ligne le 07 décembre 2005, consulté le 25 septembre 2020. URL : http:// journals.openedition.org/abstractairanica/2077

Ce document a été généré automatiquement le 25 septembre 2020.

Tous droits réservés 


\title{
« Literary canon and patterns of evaluation in Persian prose of the eve of the Mongol invasion ». Studia Iranica, 32, 1, (2003), pp. 47-76.
}

\author{
Justine Landau
}

Cet article de fond vise à établir les critères d'évaluation de la prose d'art dans l'Iran de la fin du $6^{\mathrm{e}} / 12^{\mathrm{e}}$ au début du $7^{\mathrm{e}} / 13^{\mathrm{e}} \mathrm{s}$. Dans une tradition littéraire largement dominée par la poésie, on s'est rarement interrogé sur la valeur littéraire accordée à la prose par les auteurs classiques. L'originalité de cette problématique, traitée ici avec rigueur et érudition, s'éclaire grâce aux notions élaborées par la théorie littéraire moderne, notamment les fonctions du langage définies par Jakobson, que l'A. associe avec discernement aux catégories élaborées par les auteurs classiques. L'A. s'appuie en particulier sur deux ouvrages, le Marzbān-nāma de Sa'd al-Dīn Varāvīnī et le Sindbādnāma de Zahīrī-yi Samarqandī, versions remaniées d'ouvrages antérieurs qui exhibent dans leurs préfaces leurs stratégies d'écriture, mais aussi sur des textes théoriques tels le Čahār maqāla de Niẓāmî-yi 'Arūḍī et l'anthologie bio-bibliographique (tadkira) Lubāb al-albāb de Muhammad-i 'Awfī. Les listes sélectives d'œuvres et d'auteurs proposés en modèle dans ces ouvrages participent à l'établissement d'un canon littéraire. Celui-ci influence en retour la pratique des écrivains de l'époque en suscitant l'émulation. Une norme s'élabore ainsi pour satisfaire aux exigences du «bon goût » définies par les cercles de dabir, qui jouent un rôle considérable dans la normalisation de la prose persane. Croisant ces listes référentielles, l'A. conclut à la précellence du critère stylistique et esthétique sur tout autre critère de sélection (chronologique, géographique, générique voire linguistique, non retenus). La qualité la plus prisée dans une œuvre en prose serait donc ce que l'A. rebaptise «fonction lingua-ornementale ", à une époque où la tendance est à la poétisation de la prose et à la reconnaissance de la fonction ornementale des citations arabes insérées dans les textes persans. L'A. souligne l'importance de la période dans le développement de la prose littéraire (natrr-i fannī), où l'on passe de la primauté accordée à la visée informative ou communicative à 
la valorisation de la fonction poétique. Selon une métaphore récurrente de l'époque, il s'agit de parer convenablement les "vierges nues sous un voile d'obscurité » des œuvres anciennes, pour les exposer à leur nouveau public. L'argumentation, centrée sur la problématique de la réception, est convaincante, et l'A. offre ici un panorama éclairant du système littéraire, en mettant en évidence l'existence d'une catégorie esthétique de la prose d'art à la veille des invasions mongoles.

INDEX

Thèmes : 11.1.1. Littérature persane classique

Keywords : Prose, literary tradition

Mots-clés : tradition littéraire

nompropre Sa'd al-Dīn Varāvīnī, Ẓahīrī-yi Samarqandī, Niẓāmì-yi 'Arūḍī, Muḥammad-i 'Awfī

\section{AUTEURS}

JUSTINE LANDAU

Paris 